\title{
Strategi Marketing Public Relations Studi Kajian Otonomi Daerah Skoda Indonesia Dalam Membangun Brand Awareness
}

\author{
Agung Trihartono ${ }^{1}$ \\ ${ }^{1}$ Universitas Ahmad Dahlan Yogyakarta, Indonesia
}

\begin{tabular}{ll} 
Article Info & \multicolumn{1}{c}{ ABSTRACT } \\
\cline { 1 - 3 } Article history: & $\begin{array}{l}\text { Penelitian ini bertujuan untuk mendeskripsikan bagaimana strategi } \\
\text { marketing public relations pada studi kajian otonomi daerah (skoda } \\
\text { indonesia) dalam membangun brand awareness. Penelitian ini }\end{array}$ \\
Received Feb 17, 2018 & $\begin{array}{l}\text { menggunakan metodologi penelitian kualitatif dengan bentuk } \\
\text { deskriptif. Penelitian dilakukan dengan pengumpulan data melalui }\end{array}$ \\
Accepted Apr 3, 2018 & $\begin{array}{l}\text { wawancara mendalam, kemudian dijabarkan secara deskriptif. Teknik } \\
\text { pengumpulan data yang peneliti gunakan yakni melalui wawancara, }\end{array}$ \\
\hline Keywords: & $\begin{array}{l}\text { observasi, dan studi pustaka. Hasil penelitian ini menunjukkan bahwa } \\
\text { berdasarkan data yang di dapat aktivitas Skoda Indonesia dalam }\end{array}$ \\
Strategi & membangun brand awareness adalah dengan menggunakan strategi \\
Marketing Public Relation & marketing public relations yang pada intinya menjaring pasar dengan \\
Brand Awareness & memanfaatkan people to people, mendengarkan kebutuhan pasar, dan \\
memberikan pelayanan maksimal.
\end{tabular}

This is an open access article under the CC BY-SA license.

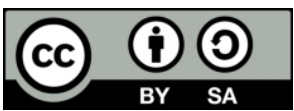

\section{Corresponding Author:}

Agung Trihartono,

Program studi Ilmu Komunikasi,

Universitas Ahmad Dahlan,

Email: agung@comm.uad.ac.id

\section{PENDAHULUAN}

Manusia merupakan mahluk sosial, sejatinya mahluk sosial akan selalu berhubungan satu dengan yang lainya. Dalam proses berhubungan tentunya dibutuhkan komunikasi yang efektif bagi kedua belah pihak. Secara umum komunikasi diartikan sebagai proses interaksi pertukaran informasi (pesan, ide, gagasan, dll) antara manusia atau kelompok satu dengan manusia atau kelompok yang lain. Maka dari itu, komunikasi sangat dibutuhkan untuk membangun hubungan baik antara perusahaan dengan pangsa pasarnya. Dalam prosesnya, komunikasi akan selalu berkembang mengikuti perkembangan zaman. Sehingga dewasa ini, dengan kemajuan teknologi yang berkembang pesat dan sangat mendukung untuk membangun hubungan antar manusia bahkan dalam jumlah banyak, menjadikan komunikasi sebagai senjata yang paling ampuh untuk membangun citra baik suatu perusahaan (Wiratno \& Santosa, 2014).

Negara Kesatuan Republik Indonesia (NKRI), atau lebih umum disebut Indonesia, adalah negara kepulauan terbesar di dunia yang terdiri dari 17.504 pulau. Menurut data dari Badan Pusat Statistika, populasi penduduk Indonesia mencapai hampir 270.054.853 jiwa pada tahun 2018. Negara ini berpenduduk terbesar keempat di dunia setelah Cina, India, dan Amerila Serikat, yang juga berpenduduk Muslim terbesar di dunia, dengan lebih dari 230 juta jiwa (Mulyati, 2005).

Tentunya untuk mengatur negara dengan populasi yang banyak dan memiliki wilayah seluas ini tidak bisa hanya diatur oleh satu sistem pemerintah pusat saja. Dibutuhkan pembagian daerah-daerah agar lebih mudah untuk mengontrol atau mengolah baik masyarakat, sumber kekayaan alam maupun juga sistem pemerintahan. Berdasarkan data dari Badan Pusat Statistik, Indonesia saat ini secara de facto terdiri dari 34 provinsi, dibagi menjadi 416 kabupaten dan 98 kota atau 7.024 daerah setingkat kecamatan, atau 81.626 daerah 
setingkat desa. Pastinya setiap daerah memiliki kultur dan permasalahan-nya sendiri, sehingga dirumuskan lah apa yang namanya Otonomi Daerah (Sumarwan et al., 2008).

Menurut UU No.32 tahun 2004, arti dari Otonomi Daerah adalah "hak, wewenang, dan kewajiban daerah otonom guna mengatur dan mengurus sendiri urusan pemerintahannya serta kepentingan masyarakat seseuai dengan undang-undang yang berlaku". Sehingga dengan demikian, setiap daerah diberikan kebebasan untuk mengatur daerahnya sendiri yang tentunya dilandasi dengan peraturan perundng-undangan. Terdapat kurang lebih 6 sumber hukum untuk mengatur terkait otonomi daerah ini, mulai dari ndang-undang, Tap MPR, maupun UUD 1945. Dengan banyaknya peraturan-peraturan dalam proses menjalankan otonomi daerah, sering kali banyak daerah-daerah yang kurang menguasai dalam menyusun atau menjalankan administrasi pemerintahan-nya. Khususnya pada daerah-daerah berkembang atau juga daerah-daerah pemekaran. Sehingga dibutuhkan pelatihan-pelatihan yang baik, guna mengembangkan SDM yang ada dari lembaga-lembaga pemerintahan seperti itu, sehingga mampu menjalankan otonomi daerahnya. Melihat hal itu, lahir lah banyak perusahaan suasta yang menjual jasa pelatihan terkait proses pengembangan dan otonomi daerah, diantaranya adalah CV. Skoda Indonesia (Aaker, 1997).

Skoda Indonesia (Studi Otonomi Daerah) merupakan salah satu perusahaan suasta yang menjual jasa peatihan-pelatihan terkait keotonomian daerah, seperti keuangan, administrasi, pengarsipan, pengembangan daerah dan lain sebagainya. Selain sudah berlebel CV, perusahaan ini juga sudah terdaftar di Kementrian dalam Negeri (Kemendagri), Kementrian Hukum dan Hak Asasi Manusia (Kemenkumham), Departemen Keuangan (Depkeu), Kementrian Pendayagunaan Aparatur Negara (Kemenpan), dan Apeksi. Marketing public relations (MPR) yang memang bertugas untuk dapat menjaring pasar seluas-luasnya, menjaga hubungan baik dengan pasar, dan juga menmbangun citra diri dari perusahaan. Dalam hal ini, MPR Skoda Indonesia mempunyai pekerjaan rumah yang cukup berat, karena untuk dapat menyentuh wilayah Indonesia seluas ini dibutuhkan company branding yang kuat agar mendapat kepercayaan dari pasar (Erdem \& Swait, 2004).

Namun dalam perjalannya dari awal berdiri hingga saat ini, Sekoda Indonesia justru tidak menggunakan media sosial internet untuk melakukan peromosi pada pelangganya. Sehingga pasar tidak dapat mengakses dan mengenali Skoda Indonesia ini di dunia maya, padahal era modern semua lembaga pemerintahan pasti menggunkan internet. Selain itu, peraturan dari Kemendagri membatasi untuk perusahaan suasta seperti ini bahwa hanya boleh berorasi selama dua tahun, kemudian difakumkan minimal satu tahun setelah itu perusahaan baru boleh beroprasi kembali. Dengan demikian proses branding dari perusahaan pun otomatis terhenti, dan pasar akan mencari perusahaan lainya, sehingga persepsi pasar tidak dapat menetap pada satu brand tertentu. Ditambah lagi persaingan pasar sangat lah banyak dan ketat. Terdapat sekitar empat puluhan lebih perusahaan sejenis hanya dalam wilayah Yogyakarta saja. Metoda, Satu Visi, dan Idea merupakan tiga besar perusahaan sejenis yang besar di Yogyakarta. Dengan. Tidak adanya penggunaan media sosial dalam melakukan promosi, ditambah lagi adanya pembatasan oprasi dari kementrian dan juga persaingan pasar yang sangat besar dan ketet. Tentunya akan sangat sulit bagi Skoda Indonesia untuk menanamkan brand awareness pada konsumenya. Sehingga dengan demikian peneliti tertarik untuk meneliti bagaimana Skoda Indonesia melakukan marketing public relation hingga membentuk brand awareness pada konsumenkonsumenya (Sri, 2013).

Pustaka pertama yaitu, skripsi yang berjudul Strategi Marketing Public Relations Citifin Multifinance Syariah Dalam Meningkatkan Brand Awareness. yang diteliti pada tahun 2017. Skripsi tersebut disusun oleh Bill Tesyar Nursallam, mahasiswa Universitas Islam Negeri (UIN) Syarif Hidayatullah Jakarta. Persamaan dengan penelitian yang peneliti akan lakukan yakni sama-sama berfokus pada strategi marketing public relations dalam meningkatkan Brand Awareness, Peneliti sama-sama menggunakan metode penelitian kualitatif dengan teknik pengumpulan data melalui wawancara, observasi, dan studi pustaka. Perbedaan hanya pada subjek, objek dan lokasi (Wijaya, 2015).

\section{METODE}

Penelitian ini menggunakan metodologi kualitatif dengan jenis deskriptif. Penelitian kualitatif bertujuan untuk menjelaskan fenomena dengan melalui pengumpulan sedalam-dalamnya(Sugiyono, 2015). Penelitian ini merupakan penelitian deskriptif, yaitu penelitian yang bertujuan menjelaskan sistem sosial, peristiwa atau hubungan sosial. Jenis penelitian ini akan mampu menangkap berbagai informasi kualitatif dengan deskripsi teliti dan penuh nuansa yang lebih berharga daripada sekedar pernyataan jumlah ataupun frekuensi dalam bentuk angka (Sutopo, 2002: 3). Peneliti akan menjelaskan secara mendalam tentang strategi yang digunakan oleh Skoda Indonesia dalam melakukan strategi marketing public relations dalam meningkatkan brand Awareness kemudian membandingkannya dengan teori yang digunakan. Penelitian ini dilakukan di kantor Skoda Indonesia. Jl. Gurami, Gg Mujagir, Nitikan, Sorosutan, Umbulharjo, Kota Yogyakarta, DIY 55162. Penelitian ini dilakukan pada bulan April - Juli tahun 2019.

Peneliti melakukan pengamatan langsung pada objek penelitian, yaitu peneliti akan mengamati secara 
langsung aktivitas-aktivitas yang ada dan mencoba memahami, mencari tahu keterkaitan strategi marketing public relations. Ini perlu dilakukan karena dari sini dapat diketahui data secara akurat, bagaimana pihak Skoda Indonesia melakukan proses branding public relations. Wawancara adalah percakapan antara periset (seseorang yang berharap mendapatkan informasi) dan informan (seseorang yang diasumsikan mempunyai informasi penting tentang suatu objek). Subjek yang akan menjadi informan peneliti yakni CEO dari Skoda Indonesia yaitu ibu Ridawati, bagian manajemen marketing Skoda Indonesia yaitu bapak Yusa dan Konsumen. Untuk mengumpulkan data-data dalam penelitian ini, peneliti memanfaatkan berbagai macam data dan teori yang dikumpulkan melalui buku-buku, internet, jurnal, skripsi dan informasi lainnya sebagai penunjang penelitian serta bahan-bahan tertulis lainnya sebagai bahan dasar penulisan.

Mengatakan pengolahan data dalam penelitian kualitatif dilakukan dengan cara mengklasifikasikan atau mengkategorikan data berdasarkan beberapa tema sesuai fokus penelitannya. Pengolahan data pada penelitian ini terdiri dari: (1) Reduksi data merupakan proses pemilihan, pemusatan perhatian pada penyederhanaan, pengabstrakan, transformasi data kasar yang muncul dari catatan-catatan lapangan. Langkah-langkah yang dilakukan adalah menajamkan analisis, menggolongkan atau pengkategorisasian ke dalam tiap permasalahan melalui uraian singkat, mengarahkan, membuang yang tidak perlu, dan mengorganisasikan data sehingga dapat ditarik dan diverifikasi. (2) Penyajian data merupakan sebagai sekumpulan informasi tersusun yang memberikan kemungkinan adanya penarikan kesimpulan dan pengambilan tindakan. Penyajian data diarahkan agar data hasil reduksi terorganisaikan, tersusun dalam pola hubungan sehingga makin mudah dipahami. Dalam melakukan penyajian data tidak sematamata mendeskripsikan secara naratif, akan tetapi disertai proses analisis yang terus menerus sampai proses penarikan kesimpulan. (3) Tahap ini merupakan tahap penarikan kesimpulan dari semua data yang telah diperoleh sebagai hasil dari penelitian. Setelah melakukan verifikasi maka dapat ditarik kesimpulan berdasarkan hasil penelitian yang disajikan dalam bentuk narasi (Sugiyono, 2016).

Melalui validitas data ini akan diketahui valid atau tidaknya suatu penelitian yang dilakukan. Teknik pemeriksaan keabsahan data pada penelitian ini menggunakan triangulasi. Triangulasi adalah teknik pemeriksaan keabsahan data yang memanfaatkan sesuatu yang lain diluar data itu untuk keperluan pengecekan atau sebagai pembanding terhadap data itu. Teknik triangulasi dapat dibedakan menjadi empat macam triangulasi sebagai teknik pemeriksaan yang memanfaatkan penggunaan sumber, metode, penyidik, dan teori. Dalam konteks penelitian ini, uji validitas data yang digunakan adalah triangulasi sumber data. menjabarkan triangulasi dengan sumber berarti membandingkan dan mengecek balik derajat kepercayaan suatu informasi yang diperoleh dengan membandingkan data hasil pengamatan dengan hasil wawancara, membandingkan apa yang dikatakan orang di depan umum dengan apa yang dikatakannya secara pribadi, dan membandingkan hasil wawancara dengan isi suatu dokumen yang berkaitan. Triangulasi sumber yang peneliti gunakan yakni narasumber yang berasal dari CEO Skoda Indonesia, bagian marketing Skoda Indonesia dan juga konsumen. Peneliti akan mewawancarai ketiga pihak dengan pertanyaan yang hampir sama, kemudian akan dilakukan perbandingan oleh peneliti apakah terdapat perbedaan data hasil wawancara yang diungkapkan antara ketiga narasumber tersebut. Selanjutnya akan dilakukan kroscek kepada pengguna jasa Skoda Indonesia terkait dengan strategi marketting Public relations dalam meningkatkan Brand Awareness yang dilakukan oleh Skoda Indonesia (Agusta, 2014).

\section{HASIL DAN PEMBAHASAN}

Strategi Marketing Public Relations Skoda Indonesia dalam Membangun Brand Awareness. Dalam melakukan praktek marketing PR, memang bisa di katakan Skoda Indonesia berbeda dengan lembaga-lembaga sejenis lainnya. Jika dilihat dari struktur organisasi resminya, Skoda Indonesia hanya di pegang oleh dua orang saja. Yang satu bertugas sebagai CEO dan eksekutor lapangan saat pelatihan, sementara yang satunya lagi fokus kepada menjaga hubungan baik kepada pelanggan dan mencari pasar-pasar baru. Meskipun terkadang hal tersebut juga dilakukan bergantian. Sementara untuk menangani pekerjaan sebagai EO yang bisa dikatakan cukup berat, Skoda Indonesia me-rekruit volenteer guna membantu pekerjaan dari Skoda Indonesia itu sendiri dan tim-tim volenteer ini berada di semua kota-kota yang biasanya digunakan Skoda Indonesia sebagai tempat pelatihannya, seperti Jakarta, Bandung, Bali, Makasar, Surabaya, Yogyakarta dan lain sebagainya.

"Kita itu gini lho pak. Sering kita itu menampung klien-klien yang biasanya kena tipu oleh lembagalembaga gaib itu. Kayak ada kasus klien dari Kalimantan, itu sudah pesan di Jakarta sana, udah tranfer. terus mereka sudah sampe sana lembaga tidak bisa dihubungi. Bingung toh, kemudia dia cari-cari, menghubungi temen-temen pemerintah di Jakarta sana. 'ehh ada gak lembaga pelatihan yang bagus, soalnya surat tugas ku sudah tak bawak ini. Dari yang Jakarta, ini coba hubungi Skoda'. Trus mereka menghubungi kita, kita layani. 'Kita bilang, bapak bisa gak datang ke Jogja? Gak bisa pak ini surat tugas saya ke Jakarta. Oke ya sudah bapak tunggu disana, biar saya hubungi tim saya yang di Jakarta, besok pagi saya kesana'. Pernah juga klien tu ada yang minta pelatihan di batam, ya udah. Tinggal hubungi temen-temen yang ada disana. Biasanya bu Ridawati tu yang banyak kenalan dimana-mana." (Muftie Yusa, Marketing Skoda Indonesia, wawancara tanggal 26 Mei 
2019) "Skoda itu flesible, dalam artian gini. Kita sudah punya jadwal, kita mengirim surat undangan yang didalamnya ada materi dan jadwal. Tapi nanti kalau suatu saat dari klient itu menginginkan waktunya di rubah, itu kita tetap melayani. Monggo silahkan mentukan waktu sendiri tapi minimal 10 orang. Karena kalau kurang dari 10 orang kan kita agak sulit ya untuk cari narasumbernya. Kadang juga mereka minta lokainya yang berubah, ada pernan minta di Surabaya, Bandung, Jakarta wes macem-macem lah. Nah itu kita juga tetap melayani. Jadi kita yang megikuti pengenya klien. Jadi mungkin klien itu jadi seneng ya sama kita, maksudnya kita selalu memberikan inovasi-inovasi lah di dalam program Skoda itu. Nanti mereka kalau pulang akan cerita ke temen-temenya" (Ibu Ridawati, CEO Skoda Indonesia, wawancara tanggal 30 April 2019)

\section{KESIMPULAN}

Berdasarkan penelitian dan analisis data yang peneliti lakukan mengenai Strategi Marketing Public Relations Skoda Indonesia dalam membangun Brand Awareness, dapat ditarik kesimpulan, sebagai berikut. Dalam melakukan strategi marketing public relations, secara struktural Skoda Indonesia memang memiliki bagian marketing dan tidak memiliki struktural resmi sebagai public relations. Namun dalam prakteknya, aktivitas, program-program dan strategi yang dilakukan oleh Skoda Indonesia bersifat seprti sebuah kerja dari praktisi public relations dalam melakukan marketing-nya, seperti membangun dan meningkatkan citra perusahaan (branding) dan terus menjaga hubungan baik dengan semua pihak terkait (relationship), seperti pemerintah, komunitas, perusahaan-perusahaan dan terkhusus kepada konsumenya. Hal-hal itu lah yang merupakan bentuk dari praktik marketing public relations.

Strategi yang dilakukan Skoda Indonesia dalam membentuk brand awareness adalah dengan menitik beratkan dalam memberikan pelayanan yang terbaik, memberikan pelayanan yang fleksible dengan menyesuaikan apa yang diinginkan oleh klien dan selalu meningkatkan kualitas produk yang ditawarkan. Itu lah yang menjadi dasar utama dari Skoda Insonesia dalam membentuk brand awarenes hingga dapat bertahan dan berkembang sampai saat ini. Selain itu, selalu menjaga hubungan baik dengan konsumen dan selalu memberikan informasi ter-update kepada konsumen yang menjadi salah satu bentuk kebutuhan konsumen. Terlebih Skoda Indonesia merupakan perusahaan yang menawarkan jasa pelatihan kepemerintahan. Peneliti menilai bahwa Skoda Indonesia masih berada dalam tingkatan Brand Recall (pengingatan kembali brand). Bahwasanya konsumen dapat mengenal Skoda Indonesia dengan baik tidak dapat dilepaskan deri nama besar CEO dan Marketing-nya sendiri, yaitu bu Ridawati dan pak Mufti Yusa. Namun karena produk dari Skoda Indonesia merupakan pelatihan jasa, sehingga sangat sulit dilepaskan dari ethos orang-orang di dalamnya. Peneliti mengganggap bahwa pencapaian ini sudah sangat luarbiasa

\section{REFERENSI}

Aaker, J. L. (1997). Dimensions of brand personality. Journal of Marketing Research. https://doi.org/10.2307/3151897

Agusta, I. (2014). Teknik Pengumpulan dan Analisis Data Kualitatif. Jurnal Studi Komunikasi Dan Media.

Erdem, T., \& Swait, J. (2004). Brand Credibility, Brand Consideration, and Choice. Journal of Consumer Research. https://doi.org/10.1086/383434

Mulyati, Y. (2005). Konsep Sistem Informasi. Jurnal Administrasi Pendidikan UPI.

Sri, H. A. (2013). PUBLIC RELATIONS DAN HUMAN RELATIONS DALAM PERSPEKTIF ILMU KOMUNIKASI. Public Relations \& Human Relations.

Sugiyono. (2015). Metode Penelitian. Metode Penelitian.

Sugiyono. (2016). Memahami Penelitian Kualitatif. Bandung: Alfabeta.

Sumarwan, U., Djunaidi, A., Aviliani, Singgih, H. C. R., Sayono, J. A., Budidarmo, R. R., \& Rambe, S. (2008). Pemasaran Strategi. In Andi Office.

Wijaya, I. S. (2015). Perencanaan dan Strategi Komunikasi. Lentera. Lentera. https://doi.org/http://dx.doi.org/10.21093/lj.v17i1.428

Wiratno, T., \& Santosa, R. (2014). Bahasa, Fungsi Bahasa, dan Konteks Sosial. Modul Pengantar Linguistik Umum. 